\title{
Oxidation of Dimethyl Ether, Methyl Formate and Bromomethane by Methylococcus capsulatus (Bath)
}

\author{
By D. I. STIRLING* AND H. DALTON \\ Department of Biological Sciences, University of Warwick, Coventry CV4 $7 A L$
}

(Received 16 May 1979; revised 5 July 1979)

\begin{abstract}
Suspensions of Methylococcus capsulatus strain Bath oxidized dimethyl ether, methyl formate and bromomethane. The rate of disappearance of dimethyl ether was enhanced up to 11-fold in the presence of co-substrates such as formaldehyde. Dimethyl ether was oxidized by the purified methane mono-oxygenase from $M$. capsulatus (Bath) to give various amounts of methanol and formaldehyde. As $M$. capsulatus (Bath) cannot grow on dimethyl ether it was concluded that this ether is a non-growth substrate which can be fortuitously oxidized. Possible reasons for the lack of growth on dimethyl ether are discussed. Methyl formate and bromomethane were oxidized by the purified methane mono-oxygenase to yield equal stoicheiometric amounts of formaldehyde and formic acid, and formaldehyde alone, respectively. Methylococcus capsulatus (Bath) grew on methyl formate but not on bromomethane and it was concluded that the latter is a non-growth substrate which can be fortuitously oxidized. Preliminary evidence is presented for carbon assimilation during the oxidation of bromomethane.
\end{abstract}

\section{INTRODUCTION}

The ability of methane-oxidizing bacteria to oxidize and utilize dimethyl ether as a sole source of carbon and energy was first reported in a review by Wilkinson (1971). Since then, the assimilation of dimethyl ether by such bacteria has been described only on a few occasions (Davey, 1971; Hazeu, 1975; Ribbons, 1975; Patel et al., 1976) although a number of reviews and papers refer to the remarks of Wilkinson $(1971,1975)$ as evidence for dimethyl ether oxidation. On the basis of the unpublished observations of Bryan-Jones \& Wilkinson (Wilkinson, 1971) and further unpublished results of Mitton involving ${ }^{18} \mathrm{O}_{2}$ incorporation, Davey (1971) proposed a pathway for methane oxidation involving dimethyl ether as an intermediate. He suggested that methane was oxidized to dimethyl ether which in turn was oxidized by a CO-sensitive oxygenase to methyl formate. Methyl formate was then hydrolysed by means of an esterase to methanol and formate. Such a mechanism would not be consistent with the ${ }^{18} \mathrm{O}$ studies of Higgins \& Quayle (1970) and, in contrast with the earlier proposals, Thomson (1974) showed that dimethyl ether was oxidized by suspensions of methane-utilizing bacteria via 2-ethoxyethanol and 2-ethoxyacetaldehyde to 2-ethoxyacetate. Furthermore, Wilkinson (1975) reported that no ${ }^{14} \mathrm{C}$ incorporation into dimethyl ether or methyl formate was detected when suspensions of various methane-utilizing bacteria were incubated with $\left[{ }^{14} \mathrm{C}\right]$ methane, although $\left[{ }^{11} \mathrm{C}\right]$ methanol was readily detectable (Wilkinson, 1975). To incorporate these findings and still retain a role for dimethyl ether as an intermediate in methane oxidation, a new scheme was suggested in which the initial product of dimethyl ether oxidation was the unstable hemi-acetal, methoxymethanol. This could either spontaneously decompose to give formaldehyde and methanol or be oxidized by the primary alcohol dehydrogenase to methyl formate (Thomson, 1974). Even with this revised hypothetical pathway there was no direct evidence for the involvement of dimethyl ether as an intermediate in methane oxidation. This, combined with the fact that studies with cell$0022-1287 / 80 / 0000-8761 \$ 02.00$ (C) 1980 SGM 
free methane mono-oxygenase systems from Methylococcus capsulatus (Bath) (Colby et al., 1977) and Methylosinus trichosporium OB3b (Tonge et al., 1977; Stirling et al., 1979) had indicated that methanol was the initial product of methane oxidation, means that the possibility of dimethyl ether being a normal intermediate in methane oxidation is very remote. Our present study is concerned with the nature of this apparently fortuitous oxidation (see Stirling \& Dalton, 1979).

Crude extracts of two organisms, Methylomonas methanica and Methylococcus capsulatus (Bath), have been reported to be capable of catalysing the disappearance of bromomethane (Colby et al., 1975; Colby \& Dalton, 1976). In both instances bromomethane oxidation was thought to be catalysed by the methane mono-oxygenase. The present paper is also concerned with the oxidation of bromomethane by suspensions of Methylococcus capsulatus (Bath) and by purified methane mono-oxygenase and attempts to determine the nature of the oxidation and its effect on the organism.

\section{METHODS}

Growth of bacteria and preparation of washed suspensions. Methylococcus capsulatus (Bath) was grown in continuous culture and cell suspensions were prepared as described previously (Stirling \& Dalton, 1979). The ability of $M$. capsulatus (Bath) to grow on dimethyl ether plus formate or methyl formate was studied using $250 \mathrm{ml}$ conical flasks containing $25 \mathrm{ml}$ sterile ammonium/mineral salts medium (Dalton \&Whittenbury, $1976)$ and various amounts of the substrates. Appropriate controls either with methane (50 $\mathrm{ml})$ as sole source of carbon or without carbon source were included. All flasks were inoculated with $0.5 \mathrm{ml}$ of a chemostat culture as described previously (Stirling \& Dalton, 1979) and incubated at $45^{\circ} \mathrm{C}$ for up to $7 \mathrm{~d}$.

Respiration studies. Respiration studies were done at $45^{\circ} \mathrm{C}$ in a Clark-type oxygen electrode (Rank Bros, Bottisham, Cambridge) with a reaction chamber of $3 \mathrm{ml}$ capacity. The reaction vessel contained $160 \mu \mathrm{M}$ sodium phosphate buffer ( $\mathrm{pH} 6 \cdot 8)$, cell suspension to give a final $A_{540}$ of $2(0.815 \mathrm{mg}$ dry wt cells) prepared as described above, and substrates and inhibitors at the final concentrations indicated.

Whole-cell oxidation studies. The assays were done in $7 \mathrm{ml}$ conical flasks essentially as described previously (Colby et al., 1977) except that extract was replaced by cell suspension ( $0.53 \mathrm{mg}$ dry wt cells). Dimethyl ether gas and the co-substrates were present at the concentrations indicated. Dimethyl ether disappearance was followed by flame ionization/gas chromatography as described previously (Colby et al., 1977).

Identification of the contaminant in dimethyl ether. The contaminant in saturated dimethyl ether solutions was identified using a Pye Series 104 flame ionization/gas chromatograph fitted with a $2 \cdot 1 \mathrm{~m}$ glass column (internal diam. $4 \mathrm{~mm}$ ) packed with Porapak N (Waters Associates, Milford, Mass., U.S.A.). The column was operated at $160^{\circ} \mathrm{C}$ with a $\mathrm{N}_{2}$ gas flow-rate of $30 \mathrm{ml} \mathrm{min} \mathrm{m}^{-1}$. The contaminant was identified by comparison of its retention time with those of authentic standards and its concentration was estimated by comparison of peak areas with the standards.

Purified methane mono-oxygenase assays. The three components of the methane mono-oxygenase from M. capsulatus (Bath) (Colby \& Dalton, 1978) were purified as follows: component C was purified to homogeneity as previously described (Colby \& Dalton, 1978, 1979) and components A and B were purified to about $95 \%$ homogeneity as judged by gel electrophoresis (unpublished results). The assays were done in $7 \mathrm{ml}$ conical flasks essentially as described previously (Colby et al.,1977). Each flask contained $1 \mathrm{ml}$ potassium phosphate buffer ( $20 \mathrm{~mm}, \mathrm{pH} 6.8), 3.4 \mathrm{mg}$ component A, $1.6 \mathrm{mg}$ component $\mathrm{B}, 0.15 \mathrm{mg}$ component $\mathrm{C}$, $5 \mu \mathrm{mol} \mathrm{NADH}$ and substrate at the concentration indicated. Methanol was identified and estimated as described by Colby et al. (1977), formaldehyde by the colorimetric method of Nash (1953), and formate by the colorimetric method of Lang \& Lang (1972).

Materials. Chemicals and biochemicals were generally of the best grade available and were obtained from sources described previously (Colby et al., 1977). Methyl formate was obtained from BDH.

\section{RESULTS AND DISCUSSION}

\section{Respiration studies with dimethyl ether}

The respiration rates observed in an oxygen electrode containing suspensions of $M$. capsulatus (Bath) with dimethyl ether $(99 \%)$ as substrate are shown in Table 1 . Very rapid oxygen consumption occurred with high concentrations of dimethyl ether $(100 \mathrm{~mm})$ even in the presence of ethyne or 8-hydroxyquinoline, both of which are potent inhibitors of methane 
Table 1. Substrate respiration studies using suspensions of $M$. capsulatus (Bath)

\begin{tabular}{lc}
\multicolumn{1}{c}{ Substrate $(\mathrm{mm})$} & $\begin{array}{c}\text { Oxidation rate } \\
\text { [nmol } \mathrm{O}_{2} \text { consumed min } \\
(\mathrm{mg} \mathrm{dry} \mathrm{wt} \mathrm{cells})^{-1}\end{array}$ \\
$\mathrm{CH}_{4}(0 \cdot 12)$ & 463 \\
$\mathrm{CH}_{4}(0 \cdot 12)+$ ethyne $(1 \cdot 2)$ & 0 \\
$\mathrm{CH}_{3} \mathrm{OCH}_{3}(100)$ & 473 \\
$\mathrm{CH}_{3} \mathrm{OCH}_{3}(0 \cdot 1,3)$ & 0 \\
$\mathrm{CH}_{3} \mathrm{OCH}_{3}(100)+$ ethyne $(1 \cdot 2)$ & 468 \\
$\mathrm{CH}_{3} \mathrm{OCH}_{3}(100)+$ ethyne $(5)$ & 334 \\
$\mathrm{CH}_{3} \mathrm{OCH}_{3}(100)+8$-hydroxyquinoline (1) & 463 \\
$\mathrm{CH}_{3} \mathrm{OCH}{ }_{3}^{*}(100)$ & 8 \\
$\mathrm{CH}_{3} \mathrm{OCH}{ }_{3}^{*}(100)+$ ethyne $(1 \cdot 2)$ & 0 \\
$\mathrm{CH}_{3} \mathrm{OCHO}(2 \cdot 5)$ & 290 \\
$\mathrm{CH}_{3} \mathrm{OCHO}(2 \cdot 5)+$ ethyne $(1 \cdot 2)$ & 0 \\
$\mathrm{CH}_{3} \mathrm{Br}(2)$ & 48 \\
$\mathrm{CH}_{3} \mathrm{Br}(2)+$ ethyne $(1 \cdot 2)$ & 0 \\
\multicolumn{2}{c}{ * Scrubbed dimethyl ether (see text). }
\end{tabular}

mono-oxygenase (Stirling \& Dalton, 1977). Only 30\% inhibition was caused by ethyne at a final concentration of $5 \mathrm{~mm}$ which was approximately five times the concentration required to inhibit methane oxidation completely.

When a solution of dimethyl ether was prepared by first scrubbing the gas through water, the oxidation rate was only $8 \mathrm{nmol} \mathrm{O}_{2}$ consumed $\min ^{-1}$ (mg dry wt cells) ${ }^{-1}$ (Table 1 ). Gas chromatographic analysis (see Methods) of the dimethyl ether solutions indicated that methanol was present at a concentration in excess of $5 \mathrm{~mm}$ in the unscrubbed solution but was completely absent from the scrubbed solution. This was confirmed when the unscrubbed solution was tested as a substrate for methanol dehydrogenase in soluble extracts of $M$. capsulatus (Bath) under optimum conditions for the enzyme in Pseudomonas M27 (Anthony \& Zatman, 1964). A rapid reduction of 2,6-dichlorophenolindophenol was observed which was not inhibited by ethyne. The scrubbed dimethyl ether solution gave no similar reduction.

\section{Dimethyl ether disappearance with whole-cell suspensions}

The rate of disappearance of dimethyl ether was proportional to its concentration up to $10 \mathrm{~mm}$; higher concentrations had little effect on the rate. The low rate of dimethyl ether disappearance (Table 2) was similar to the oxidation rate observed when monitoring oxygen consumption using the scrubbed dimethyl ether solution (Table 1). In the presence of a co-substrate which could generate reducing power, the rate of dimethyl ether disappearance increased markedly (Table 2). These results effectively eliminate the possibility that the low rate of oxidation of dimethyl ether with whole organisms was due to the toxicity of substrate or product. A more probable explanation would be either inability to take up the substrate or inability to generate reducing power for the mono-oxygenase from the subsequent oxidation of the substrate.

\section{Oxidation of dimethyl ether by purified methane mono-oxygenase}

No products from dimethyl ether oxidation by whole-cell suspensions or cell-free extracts (Colby et al., 1977) of $M$. capsulatus (Bath) were detected by the gas chromatographic techniques described in Methods. To resolve this situation, dimethyl ether oxidation was studied using purified methane mono-oxygenase (Table 3). Methanol and formaldehyde were produced from dimethyl ether, but not in equal amounts as would be expected for these two products. This was thought to be due to the oxidation of the resultant methanol to 
Table 2. Rates of dimethyl ether disappearance with suspensions of M. capsulatus (Bath)

Substrate(s) $(\mu \mathrm{mol})$
$\mathrm{CH}_{3} \mathrm{OCH}_{3}(10)$
$\mathrm{CH}_{3} \mathrm{OCH}_{3}(10)+\mathrm{CH}_{3} \mathrm{OH}(4)$
$\mathrm{CH}_{3} \mathrm{OCH}_{3}(10)+\mathrm{HCHO}(4)$
$\mathrm{CH}_{3} \mathrm{OCH}_{3}(10)+\mathrm{HCOOK}(4)$

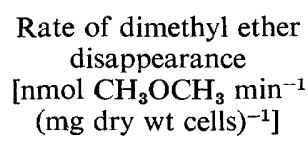

Rate of dimethyl ether disappearance [nmol $\mathrm{CH}_{3} \mathrm{OCH}_{3} \mathrm{~min}^{-1}$ (mg dry wt cells) ${ }^{-1}$ ]

175

125

223

Table 3. Oxidation studies using purified methane mono-oxygenase from M. capsulatus (Bath)

Assays were done as described in Methods.

$$
\begin{gathered}
\text { Substrate } \\
(\mu \mathrm{mol} \text { per } \\
\text { reaction flask })
\end{gathered}
$$

$\mathrm{CH}_{4}$ (134)

$\mathrm{CH}_{3} \mathrm{OCH}_{3}$ (3)

$\mathrm{CH}_{3} \mathrm{OCHO}(2)$

$\mathrm{CH}_{3} \mathrm{Br}(2 \cdot 5)$

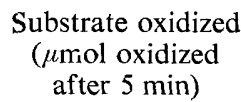

ND

$1 \cdot 05$

$1 \cdot 1$

$0 \cdot 97$

$\begin{gathered}\text { Product } \\ (\mu \mathrm{mol} \text { formed } \\ \text { after } 5 \mathrm{~min})\end{gathered}$
$\mathrm{CH}_{3} \mathrm{OH}(2 \cdot 02)$
$\mathrm{HCHO}(1 \cdot 05)$
$\mathrm{CH}_{3} \mathrm{OH}(0 \cdot 38)$
$\mathrm{HCHO}(1 \cdot 75)$
HCHO $(1 \cdot 1)$
HCOOH $(1 \cdot 05)$
HCHO $(1 \cdot 0)$

Activity (nmol substrate utilized $\mathrm{min}^{-1}$ )

$614^{*}$

208

220

243

ND, Not determined.

* Rate of methane oxidation was determined from the amount of product formed.

formaldehyde by the methane mono-oxygenase, as methanol has been shown to be a substrate for the enzyme (Colby et al., 1977). The results of the assay containing methane and the purified enzyme (Table 3 ) confirm this explanation as formaldehyde was produced from methanol, the initial product from methane oxidation. Similar assays continued for longer than $5 \mathrm{~min}$ still showed a linear increase in the total amount of products but the proportion of formaldehyde increased.

The oxidation of dimethyl ether to methanol and formaldehyde probably proceeds via the unstable hemiacetal methoxymethanol which dismutates to give equal amounts of methanol and formaldehyde. Interestingly, no methyl formate was detected from dimethyl ether oxidation, thus contradicting the first revised methane oxidation pathway envisaged by Davey (1971), at least in this species.

Dimethyl ether can be oxidized, albeit very poorly, by suspensions of $M$. capsulatus (Bath) and readily oxidized by extracts and purified methane mono-oxygenase preparations, although it is a non-growth substrate (Stirling \& Dalton, 1979). Meyers \& Ribbons (1978) recently reported that $M$. capsulatus strain Texas could not grow on dimethyl ether although it was oxidized by cell suspensions. Dimethyl ether is clearly a non-growth substrate which can be fortuitously oxidized [as defined by Stirling \& Dalton (1979)]. To determine whether any carbon assimilation can occur as a result of dimethyl ether oxidation will require ${ }^{14} \mathrm{C}$ incorporation studies. If methanol and formaldehyde are the products of dimethyl ether oxidation in vivo, as would seem likely, it is possible that some carbon assimilation might occur. This poses the problem, why does $M$. capsulatus (Bath) not grow on dimethyl ether? If methanol and formaldehyde are the products of dimethyl ether oxidation in vivo, then the explanation, given above, that the low rate of oxidation by intact bacteria was due to the lack of reductant generated from the complete oxidation of dimethyl ether, cannot be correct. Both methanol and formaldehyde could generate NADH from their subsequent 
oxidation by the $\mathrm{NAD}^{+}$-linked formaldehyde and formate dehydrogenases (Stirling \& Dalton, 1978). This suggests that the low rate of oxidation of dimethyl ether by suspensions of $M$. capsulatus (Bath), and consequently the inability to grow on dimethyl ether, is the result of either the organisms being relatively impermeable to dimethyl ether or that the products of the oxidation in vivo are not methanol and formaldehyde. The latter explanation must remain a possibility since no products from dimethyl ether oxidation in vivo have been detected. The fact that up to 11-fold increases in the rates of dimethyl ether disappearance with $M$. capsulatus (Bath) suspensions were observed in the presence of a co-substrate (Table 2) could suggest the involvement of an active transport mechanism for substrate uptake. If this was the case then it should be possible to grow M. capsulatus (Bath) on dimethyl ether in the presence of an exogenous energy source. Attempts to grow $M$. capsulatus (Bath) on dimethyl ether in the presence of various concentrations of potassium formate gave inconsistent results. Growth, albeit sparse, was observed in a number of flasks containing formate at low concentrations. The inconsistencies were probably the result of the toxic nature of formate at comparatively low concentrations (e.g. $5 \mathrm{~mm}$ ). Dimethyl ether is fairly lipid-soluble and one would not expect a priori that an active transport mechanism would be necessary for the substrate to enter the cell.

\section{Validity of reports of dimethyl ether oxidation}

The results obtained for dimethyl ether oxidation when assayed by oxygen consumption raise possible doubts about the validity of four other reports of dimethyl ether oxidation by methane-utilizing bacteria (Davey, 1971; Hazeu, 1975; Ribbons, 1975; Patel et al., 1976) in which dimethyl ether oxidation was monitored by oxygen consumption. None of these workers referred to the purity of gas used; although its purity in the present study was supposed to be $99 \%$, it contained a contaminant which could accumulate to significant concentrations during the preparation of gas-saturated buffer solutions. Methanol contamination of dimethyl ether solutions was recently reported by Meyers \& Ribbons (1978) who obtained similar misleading results during respiration studies with $M$. capsulatus (Texas). It is therefore suggested that all oxidation studies involving dimethyl ether should, where possible, measure either dimethyl ether disappearance or the formation of products.

\section{Oxidation of methyl formate}

As methyl formate had been proposed as an intermediate in methane oxidation (Davey, 1971), the oxidation of this compound by M. capsulatus (Bath) was investigated. Methyl formate was oxidized readily by whole-cell suspensions (Table 1) and, as with the other mono-oxygenase substrates tested, the oxidation was potently inhibited by ethyne. When assayed with purified methane mono-oxygenase, methyl formate was again readily oxidized (Table 3), yielding formaldehyde and formic acid and not methanol and formic acid as predicted or reported by others (Davey, 1971; Wilkinson, 1975; Meyers \& Ribbons, 1978).

If formaldehyde was produced from methyl formate oxidation in vivo it is possible that $M$. capsulatus (Bath) could grow on methyl formate as sole source of carbon and energy. We found that $M$. capsulatus (Bath) could indeed consistently grow on methyl formate, although only when the substrate concentration was between 5 and $10 \mathrm{~mm}$. With lower or higher concentrations no growth was ever observed. This was a surprising result in view of the inability of $M$. capsulatus to grow on dimethyl ether, but nevertheless provides a potentially useful tool for the further study of $\mathrm{C}_{1}$ metabolism in $M$. capsulatus (Bath), for instance by selecting for $M$. capsulatus (Bath) mutants which lack methanol dehydrogenase.

Methylococcus capsulatus (Texas) has recently been reported to grow on, and oxidize, methyl formate (Meyers \& Ribbons, 1978); however, on the evidence of studies with cell-free extracts, these authors proposed that methyl formate was oxidized by the primary alcohol dehydrogenase as opposed to the methane mono-oxygenase. 


\section{Oxidation of bromomethane}

Suspensions of $M$. capsulatus (Bath) can catalyse bromomethane disappearance, the rate of which is not increased by the presence of formaldehyde (Stirling \& Dalton, 1979). The results in Table 1 show that the oxidation of bromomethane by suspensions of $M$. capsulatus (Bath) was completely inhibited by ethyne, suggesting that this oxidation was catalysed by the methane mono-oxygenase. To confirm this, bromomethane oxidation was monitored using a purified methane mono-oxygenase preparation. Bromomethane was stoicheiometrically oxidized to formaldehyde (Table 3), presumably via the unstable intermediate bromomethanol which would dismutate to give formaldehyde.

Attempts to grow M. capsulatus (Bath) on bromomethane were unsuccessful (Stirling \& Dalton, 1979), probably due to the toxicity of bromide ions produced from the dismutation of bromomethanol to formaldehyde. This view was supported by results obtained from attempts to grow $M$. capsulatus (Bath) on methane in the presence of various amounts of bromine or bromomethane. Several flasks were set up as for the growth studies (see Methods) with methane as the carbon source. Bromine or bromomethane $(5,10$ or $50 \mu \mathrm{mol})$ was added to flasks and these, together with appropriate control flasks, were inoculated and incubated as before. Growth was observed only in flasks containing methane alone. Nevertheless, as formaldehyde is the first stable intermediate of bromomethane oxidation it is possible that carbon assimilation could result from the oxidation pathway. Preliminary experiments using bromo $\left[{ }^{14} \mathrm{C}\right]$ methane showed that carbon from the bromomethane was incorporated into cell material (Stirling, 1978). Therefore, for $M$. capsulatus (Bath) bromomethane is a non-growth substrate which can be fortuitously oxidized to provide some assimilable carbon (see Stirling \& Dalton, 1979).

This work was funded through an S.R.C. Research Grant to H. Dalton. We thank Mr R. W. Foster for his excellent technical assistance and Dr J. Colby for providing purified component $\mathrm{C}$ of the methane mono-oxygenase.

\section{REFERENCES}

Anthony, C. \& ZATMAN, L. J. (1964). The microbial oxidation of methanol. II. The methanol-oxidizing enzyme of Pseudomonas sp. M27. Biochemical Journal 96, 614-621.

Colby, J. \& Dalton, H. (1976). Some properties of a soluble methane mono-oxygenase from Methylococcus capsulatus strain Bath. Biochemical Journal 157, 495-497.

Colby, J. \& Dalton, H. (1978). Resolution of the methane mono-oxygenase of Methylococcus capsulatus (Bath) into three components. Purification and properties of component $\mathrm{C}$, a flavoprotein. Biochemical Journal 171, 461-468.

Colby, J. \& Dalton, H. (1979). Characterization of the second prosthetic group of the flavoenzyme $\mathrm{NADH}$-acceptor reductase (component C) of the methane mono-oxygenase from Methylococcus capsulatus (Bath). Biochemical Journal 177, 903-908.

Colby, J., Dalton, H. \& Whittenbury, R. (1975). An improved assay for bacterial methane monooxygenase: some properties of the enzyme from Methylomonas methanica. Biochemical Journal 151, 459-462.

Colby, J., Stirling, D. I. \& Dalton, H. (1977). The soluble methane mono-oxygenase of
Methylococcus capsulatus (Bath). Its ability to oxygenate $n$-alkanes, $n$-alkenes, ethers, and alicyclic, aromatic and heterocyclic compounds. Biochemical Journal 165, 345-402.

Dalton, H. \& Whittenbury, R. (1976). The acetylene reduction technique as an assay for the nitrogenase activity in the methane oxidizing bacterium Methylococcus capsulatus strain Bath. Archives of Microbiology 109, 147-151.

DaveY, J. F. (1971). A study of methane oxidizing bacteria. Ph.D. thesis, University of Edinburgh.

HAzEU, W. (1975). Some cultural and physiological aspects of methane-utilizing bacteria. Antonie van Leeuwenhoek 41, 121-134.

Higgins, I. J. \& QuAYle, J. R. (1970). Oxygenation of methane by methane-grown Pseudomonas methanica and Methanomonas methanooxidans. Biochemical Journal 118, 201-208.

LANG, E. \& LANG, H. (1972). Spezifische Farbreaktion zum direkten Nachweis der Ameisensäure. Zeitschrift für analytische Chemie 260, 8-10.

Meyers, A. J., JR \& Ribbons, D. W. (1978). Evaluation of the 'dimethyl ether pathway' for methane metabolism. Abstracts of the 78th Annual Meeting, p. 184. Washington: American Society for Microbiology. 
NASH, T. (1953). The colorimetric estimation of formaldehyde by means of the Hantzsch reaction. Biochemical Journal 55, 416-421.

Patel, R. N., Hou, C. T. \& Felix, A. (1976). Inhibition of dimethyl ether and methane oxidation in Methylococcus capsulatus and Methylosinus trichosporium. Journal of Bacteriology 126, 1017-1019.

RibBons, D. W. (1975). Oxidation of $\mathrm{C}_{1}$-compounds by particulate fractions from Methylococcus capsulatus: distribution and properties of methanedependent reduced nicotinamide adenine dinucleotide oxidase (methane hydroxylase). Journal of Bacteriology 122, 1351-1363.

StIRLing, D. I. (1978). Oxidation of carbon compounds by Methylococcus capsulatus. Ph.D. thesis, University of Warwick.

Stirling, D. I. \& Dalton, H. (1977). Effect of metal-binding agents and other compounds on methane oxidation by two strains of Methylococcus capsulatus. Archives of Microbiology 114, 71-76.

Stirling, D. I. \& Dalton, H. (1978). Purification and properties of an NAD(P)+-linked formaldehyde dehydrogenase from Methylococcus capsulatus (Bath). Journal of General Microbiology 107, 19-29.
Stirling, D. I. \& Dalton, H. (1979). The fortuitous oxidation and cometabolism of various carbon compounds by whole-cell suspensions of Methylococcus capsulatus (Bath). FEMS Microbiology Letters 5, 315--318.

Stirling, D. I., Colby, J. \& Dalton, H. (1979). A comparison of the substrate and electron-donor specificities of the methane mono-oxygenases from three strains of methane-oxidizing bacteria. Biochemical Journal 177, 361-364.

Thomson, A. W. (1974). Aspects of ethane metabolism in methylobacteria. Ph.D. thesis, University of Edinburgh.

Tonge, G. M., Harrison, D. E. F. \& Higgins, I. J. (1977). Purification and properties of the methane mono-oxygenase enzyme system from Methylosinus trichosporium OB3b. Biochemical Journal 161, 333-344.

WiLkinson, J. F. (1971). Hydrocarbons as a source of single cell protein. Symposia of the Society for General Microbiology 21, 15-46.

Wilkinson, J. F. (1975). Physiological studies of bacteria grown on methane. In Microbial Growth on $C_{1}$ Compounds, pp. 45-58. Edited by the organizing committee. Japan: The Society of Fermentation Technology. 